\title{
TERCEIRIZAÇÃO/PARCERIA E SUAS IMPLICAÇÕES NO ÂMBITO JURIDICO-SINDICAL
}

* Márcia da Silva Costa

Terceirização no Brasil - os desafios de uma nova cultura de parceria e de relações jurídico-sindicais.

Brazilian outsourcing - the challenges of a new culture of partnership and of juridical and trade unions relations.

PALAVRAS-CHAVE:

Terceirização, especialização/ racionalização de recursos, parceria, intermediação de mãode-obra, conquistas trabalhistas.

\section{KEY WORDS:}

Outsourcing, specialization rationalization of resources partnership, labour force intervention, labour conquests.

* Mestre em Administração de Empresas pela Universidade Federal da Paraiba.
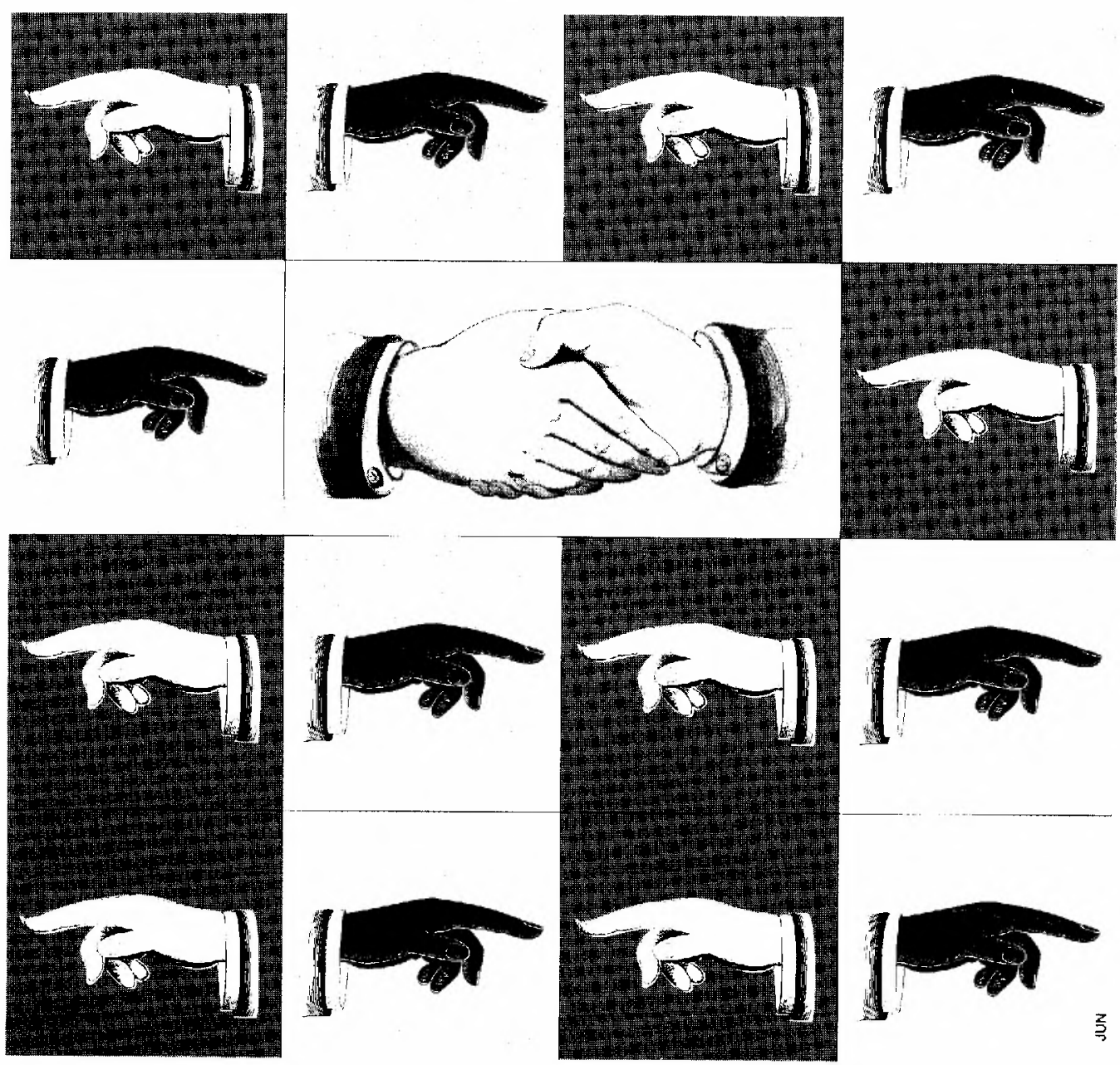
O tema Terceirização tem estado em evidência no meio empresarial, acadêmi$\mathrm{co}$, jurídico e sindical e tem simultaneamente se fixado como uma eficiente prática de flexibilidade organizacional na busca da especialização e racionalização de recursos. Embora envolvida por certa parcela de modismo e ancorada em conceitos pouco condizentes à realidade da cultura e prática empresarial brasileira, a Terceirização ou prática de comprar externamente produtos e serviços necessários ao processo produtivo tem ganhado espaço em áreas tradicionalmente executadas por funcionários e recursos da própria empresa. O cerne das discussões, entretanto, perpassa a maneira de como as empresas entendem e efetivam Terceirização, mormente no tocante aos aspectos de interação entre elas e seus fornecedores no que concerne ao estabelecimento de um relacionamento de parceria, e das atitudes destes para com os trabalhadores envolvidos no processo.

No Brasil, as diretrizes de política industrial, historicamente direcionadas para o fechamento da economia à concorrência internacional, favoreceram enormemente o processo de verticalização de seu parque industrial. Fortemente amparadas por subvenções de Governo, por reservas de mercado e pela fraca concorrência, as empresas brasileiras se descuidaram em acompanhar os padrões internacionais de qualidade e produtividade $e$ em modernizar seus processos de produção e de gestão.

Hoje, fatores como o agravamento do quadro recessivo, atrelado ao emergente ambiente de globalização da economia, impulsionado pela política de redução de tarifas, implementadas a partir de 1990 e, por conseguinte, a progressiva abertura de mercado à competição internacional, têm forçado as empresas a repensarem suas estruturas organizacionais e suas estratégias de negócios, numa busca enérgica da redução de custos e da competitividade de seus produtos. Conceitos até então pouco evidenciados, como qualidade, produtividade, racionalização de custos, direitos do consumidor, são agora extremamente necessários à sobrevivência e modernidade das indústrias nacionais, em grande parte ultrapassadas tecnologicamente. Nesta perspectiva, a Terceirização ganha importância num momento em que as empresas precisam racionalizar recursos, redefinir suas operações, funcionar com estruturas mais enxutas e flexíveis. Surge, então, como um dos instrumentos de auxílio à necessária reestruturação organizacional, ao incremento da produtividade e competitividade e à busca da identidade e comprometimento com a vocação precípua da empresa.

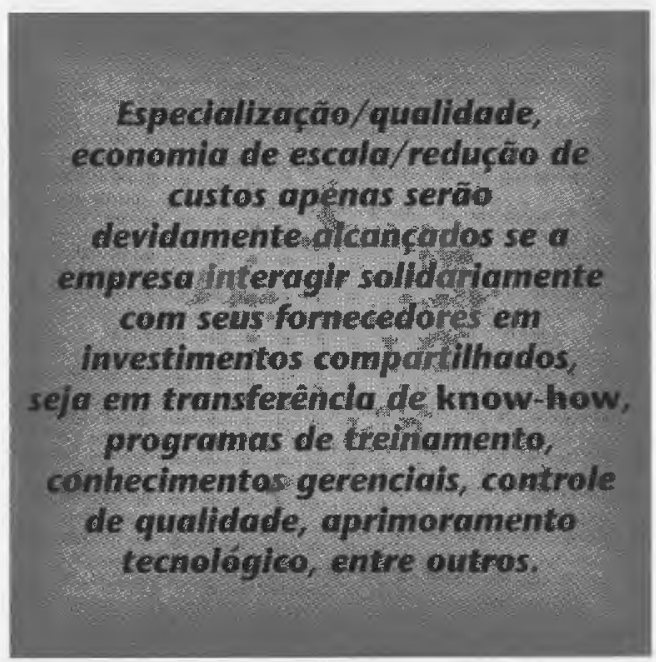

A Terceirização no Brasil tem sido tratada de forma polêmica e não regular, muitas vezes praticada de forma precária ou desvirtuada de seus preceitos básicos. O Sindicato dos Metalúrgicos do ABC Paulista', em diagnóstico sobre o tema, afirma que o conceito de modernidade e de cooperação interempresarial no Brasil demonstra na realidade resultados precários, isto por causa "... dos baixos investimentos realizados no país e da existência de uma cultura empresarial fortemente marcada pelo imediatismo dos lucros elevados e pela constante desvalorização do trabalho e do trabalhador". A polêmica daí resultante envolve, de um lado, o embate das mobilizações sindicais num ambiente de crise econômica e de um regime jurídico-trabalhista conservador e pouco flexível, e, de outro, exige todo um processo de mudança na cultura $\mathrm{e}$ comportamento das empresas no tocante ao relacionamento destas com seus fornecedores ou terceiros e à visão tradicional das relações organizacionais e de trabalho.
1. O Sindicato dos Metalúrgicos do ABC Paulista, 1982, p. 35. 
PARCERIA ISPECIALIZACAO

RACIONALIZACAO DE RECURSOS

A grande tendência no meio empresarial é buscar a excelência naquilo que a empresa sabe fazer de melhor, no que lhe é mais estratégico. É concentrar todos os seus esforços no aprimoramento e desenvolvimento do seu produto final. A horizontalização da estrutura produtiva, portanto, é condição necessária. Por outro lado, isto significa o desmonte de estruturas inteiras onde os custos de manutenção são altos e o retorno dos investimentos não é compensatório. Por esta premissa, montar e manter estruturas próprias para atender atividades não diretamente relacionadas com o objetivo principal da empresa, mormente as chamadas atividades de apoio (alimentação dos funcionários, serviço médico, limpeza e conservação de prédios etc.) e arcar com todos os custos patrimoniais e administrativos a elas inerentes, mostram-se hoje decisões técnica e economicamente inviáveis. São atividades passíveis de serem transferidas para terceiros. Assim, a Terceirização possibilita que uma empresa concentre recursos na sua atividade-fim e, por conseguinte, uma maior especialização e qualificação dos seus produtos. Ao transferir atividades-meio para terceiros especializados, a empresa passa a direcionar esforços para as áreas diretamente relacionadas ao seu negócio principal ou estratégico, para as áreas em que tem um maior domínio e, ao mesmo tempo, racionaliza recursos à medida que elimina ou reduz custos de manter estruturas operacionais e de gerenciamento destas atividades. Por outro lado, neste processo de transferência, a atividade-meio da empresa contratante constitui atividade-fim da empresa contratada, presumivelmente mais especializada, possuidora de melhor know-how e qualificação técnica para atender e buscar continuamente o aprimoramento dos produtos que fornece. No entanto, implementar eficientemente tal transferência requer o estabelecimento de uma relação interativa entre comprador $\mathrm{e}$ vendedores ou fornecedores. Isto porque uma empresa que compra parte dos serviços e produtos que se incorporam ao seu produto final depende da qualidade dos mesmos e evidentemente dos subcontratantes que os fornecem. Existe, portanto, uma interdependência intrínseca na relação empresa contratante/fornecedores que exige a implementação de uma política de parceria e apoio mútuo ao alcance de objetivos, que é vital no processo.

Especialização/qualidade, economia de escala/redução de custos apenas serão devidamente alcançados se a empresa interagir solidariamente $\mathrm{com}$ seus fornecedores em investimentos compartilhados, seja em transferência de know-how, programas de treinamento, conhecimentos gerenciais, controle de qualidade, aprimoramento tecnológico, entre outros. Por este aspecto, um processo de terceirização ou "parceirização", não deve se ater tão-somente às atividades menos importantes da empresa, de forma a considerar apenas alguma economia opcracional calcada na redução de custos financeiros. Ele deve evoluir sobre as operações básicas da organização, especialmente nos casos $\mathrm{cm}$ que a empresa transfere parte de seu processo produtivo. Daí que a formação de parceiros constitui necessariamente política de médio e longo prazos, o que implica que, para certas atividades ou produtos, é mais vantajosa a exclusividade de fornecedores e, neste ponto, a implementação de uma política de parceria pressupõe, acima de tudo, que se estabeleça uma relação de confiança e convergência de objetivos.

No Brasil, algumas poucas empresas estão abertas a práticas gerenciais mais modernas. Todavia, para a grande maioria, isto implica inevitavelmente mudanças radicais na mentalidade e cultura empresarial. Algumas empresas, entretanto, já estão absorvendo este novo sentido da parceria através da celebração de contratos de fornecimento com garantia de qualidade, do aperfeiçoamento em conjunto de produtos ou serviços, da transferência de conhecimentos e know-how etc.

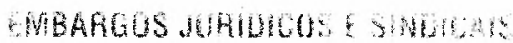 T TPCEIRILACAO}

Em meio às dificuldades financeiras, muitas empresas vêem a Terceirização como a maneira mais rápida e eficaz de reduzir custos fixos através apenas do enxugamento do seu quadro de pessoal. É certo que a transferência de serviços para terceiros, principalmente aqueles que não demandam tecnologia específica, repercu- 
tem num curto prazo importantes reduções nos custos de mão-de-obra e encargos previdenciários, cujas responsabilidades são repassadas para o fornecedor. De outro lado, o imediatismo destas decisões sem a observância dos parâmetros que permeiam os padrōes de qualidade e garantia de fornecimento e as exigibilidades técnico-econômicas e jurídicas que norteiam os contratos, a esperada redução de custos pode transformar-se em elevados prejuízos, seja quanto à conformidade do produto ou serviço comprado, seja quanto a questões jurídico/trabalhistas e sindicais. Com relação a estes dois últimos aspectos, é fato que a contratação de empresas para prestação de serviços não é prática recente no país. A Terceirização vem consolidar tal prática como um importante segmento da economia, uma vez que abre espaço para formação e desenvolvimento de novas empresas. A polêmica jurídica se baseia nos casos em que há pura intermediação de mão-de-obra e desrespeito aos direitos trabalhistas dos empregados envolvidos. A adequada Terceirizaçāo pressupõe que as empresas prestadoras de serviço desenvolvam atividades lícitas, sejam economicamente independente dos seus contratantes e responsáveis pela contratação, gerenciamento, remuneraçāo e pelos demais encargus trabalhistas dos seus empregados.

Os reclames trabalhistas, porém, vêm se constituindo num dos maiores entraves à Terceirização no país. As decisões sobre os mesmos vêm, até então, sendo relegadas à jurisprudência dos tribunais, basicamente respaldadas por duas correntes doutrinárias: uma, de origem conservadora, que encontra respaldo na inflexibilidade doutrinária da legislação trabalhista, e que tradicionalmente considera (excetuando-se os casos de serviço temporário - Lei 6.019 e vigilância - Lei 7.102) a empresa que contrata mão-de-obra via empresa interposta como titular ou fiadora das obrigaçōes desta para com seus empregados. Esta posição de juristas e doutrinadores se apóia no enunciado da Súmula 256/86 do Tribunal Superior do Trabalho. ${ }^{2}$ A segunda corrente, mais inovadora, de cunho neoliberal e propulsora dos atuais debates acerca da proposta de flexibilização da Legislação Trabalhista, argumenta que a Justiça do Trabalho não pode permanecer inócua à realidade dos fatos econômicos e sociais do país que tem provocado o surgimento de novas formas de contratação e de relações de trabalho. Assim, as decisões jurídicas tendem a enfocar diferenciadamente os reclames trabalhistas, de forma tal, que vem aumentando o número de casos em que não é considerado o vínculo empregatício. Por outro lado, a questão perpassa pela polêmica mais abrangente da flexibilização da norma trabalhista, que tramita

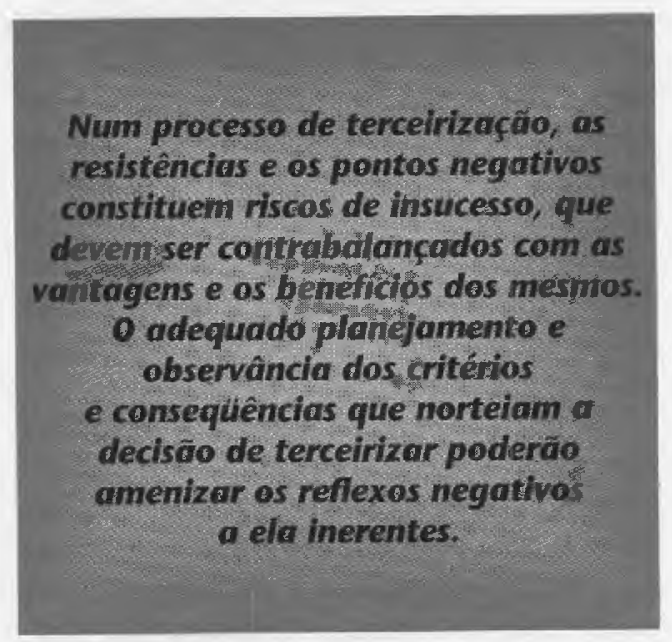

no Poder Legislativo em forma de Projetos de Lei que a atualize e a adapte à realidade socioeconômica do país.

Quanto ao posicionamento sindical, é notório e inevitável reconhecer o poderio das mobilizações sindicais das diversas categorias na busca dos direitos dos trabalhadores em face de melhores condições de trabalho, de nível de emprego e reivindicações salariais. Como também, é irreversível o quadro de reestruturação das empresas e da horizontalização de seu processo produtivo. Notadamente, as reivindicacões sindicais têm legitimidade à medida que a terceirizacão é praticada como forma de intermediação de mãode-obra. As maiores contestações se baseiam no fato de que o trabalhador do terceiro, normalmente sem representatividade sindical, embora exercendo as mesmas atividades, nãu absorve as conquistas trabalhistas e salariais do trabalhador da empresa contratante e que, além dos reflexos imediatos no nível de emprego, num longo prazo, as conseqüências mais redundantes seriam a de-
2. TRIBUNAL SUPERIOR DO TRABALHO, Súmula 256/86 Contrato de Prestação de Serviços Salvo os casos de trabalho temporário e de serviço de vigilância, previstos nas Leis 6.019 de 30.01 .74 e 7.102 de 20.06.83, é ilegal a contrataçāo de trabalhadores por empresa interposta, formando-se o vinculo empregatício diretamente com o tomador dos serviços. 
teriorização das condições de trabalho, a queda do nível de renda e qualidade de vida dos trabalhadores.

A ameaça de desemprego, diante do quadro recessivo da economia, é sem dúvida o ponto crucial da resistência sindical às decisões de empresas que terceirizam e demitem sem ao menos considerar as bases representativas de seus trabalhadores. Todavia, não necessariamente, um processo de terceirização implica demissôes, uma vez que na reestruturação de seu quadro uma empresa pode se valer de outros mecanismos para o aproveitamento de seu pessoal, estabelecendo políticas internas de realocação, incentivo à aposentadoria, incentivo à demissão voluntária, estímulo à criação de empresas fornecedoras pelos próprios funcionários, reaproveitamento de pessoal nas empresas contratadas, entre outros. O desemprego tem sua causa maior num ambiente de retração cconômica e empresas "inchadas".

Os conflitos entre as relações de poder das representatividades sindical e empresarial vêm, em sua maioria, sendo regulados institucionalmente ou por interveniência apaziguadora do Estado. Por outro lado, o amadurecimento dos processos negociativos entre estes mesmos grupos, tende a marcar um ponto de equilibrio entre os diferentes interesses por eles defendidos.

A grande estratégia, porém, é que na decisão de terceirizar a empresa informe, avalie, discuta e negocie com todos os participantes do processo, incluindo aí, as bases sindicais. Neste ponto, a flexibilidade nas negociações, na busca dos fatores que contrabalancem os interesses dos empresários e dos trabalhadores, é prática fundamental ao abrandamento dos impasses sindicais, sociais e até mesmo jurídicos, conseqüentes de um processo de terceirização.

\section{WAMTAETSSE RISCOS UA TERCEIRIZACAO}

Indiscutivelmente, no Brasil, o que mais induz as empresas a imergir num processo de terceirização é a perspectiva de redução de custos operacionais fixos de suas atividades. No entanto, como já comentado, a concepção de terceirizar com intuito apenas de reduzir custos num curto pra$z o$, principalmente os atrelados à política de corte de pessoal, constitui decisão inviável e propensa a embargos jurídicos. Ainda assim, um processo de terceirização devidamente planejado permite o alcance de resultados positivos concretos, como: racionalização da estrutura organizacional da empresa e a conseqüente redução de níveis hierárquicos e custos administrativos ou custos fixos; aprimoramento tecnológico e dos padrões de qualidade e produtividade, tanto dos itens terceirizados, pressupondo-se que estes serão fornecidos por especialistas, quanto dos efetuados pela própria empresa, que passa a concentrar recursos na sua atividade-fim; processo de decisão mais ágil e flexível; transferência de conhecimentos produtivos e administrativos; desenvolvimento de novos produtos/know-how; diminuição dos riscos de obsolescência de equipamentos; redução de custos em infra-estrutura/desmobilização de ativos; redução de controles; economia de escala. Da perspectiva macroeconômica podem-se destacar: incentivo à criação de novos mercados para as micro e pequenas empresas; criação de empregos; maior geração de impostos; maior qualificação da mão-de-obra existente no mercado; aumento da competitividade; redistribuição de renda.

Por outro lado, o risco econômico é inerente a toda atividade empresarial. Daí que nenhum conceito administrativo, nenhuma decisão de investimento é totalmente cercada de pontos vantajosos ou imune à resistência das pessoas (cultura e comportamentos) e de variáveis cstruturais (conjuntura econômica, política e social, estrutura de poder, aspecto jurídicoconstitucional, capacitação tecnológica, etc.). Existc, portanto, uma enorme interrclação de fatores que influenciam as decisōes empresariais e seus resultados. Analogamente, num processo de terceirização, as resistências e os pontos negativos constituem riscos de insucesso, que devem ser contrabalaçados com as vantagens e os benefícios do mesmo. $\mathrm{O}$ adequado planejamento e observância dos critérios e conseqüências que norteiam a decisão de terceirizar poderão amenizar os reflexos negativos a cla inerentes. Dentre os aspectos mais significativos que dificultam a Terceirização podem-se destacar: dificuldade de integração das culturas do contratante e do fornecedor; risco na escolha dos par- 
ceiros (negligência e incapacitação, inexperiência); risco da não conformidade do produto ou serviço (qualidade); não cumprimento das cláusulas contratuais como acordadas; risco de desemprego e não absorção da mão-de-obra na mesma proporção; reclames jurídico-trabalhistas; confronto sindical.

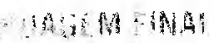

As rápidas transformações advindas do desenvolvimento tecnológico e do aprimoramento das comunicações e da informática, o acirramento concorrencial dos mercados, a retração econômica em escala mundial e a necessidade premente de oferecer economicamente produtos e serviços que satisfaçam às necessidades dos consumidores são fatos recentes que serviram de alavancas para um grande processo de mudanças na vida organizacional. Nas cconomias contemporâneas, o sistema out-sourcing, ou "especialização flexível," termos empregados nos Estados Unidos e Europa para definir Terceirização, vem se associar aos novos modelos e técnicas de gestão participativa que primam pela "focalização" nas atividades estratégicas da empresa e pela sua reestruturação organizacional, na busca da redução de custos, eficiência produtiva e flexibilidade gerencial.

Neste contexto, Terceirização é, essencialmente, um processo de gestão participativa, que requer mudanças na cultura, na mentalidade e no comportamento das partes envolvidas, para o alcance de objetivos propostos. A velha máxima do querer levar vantagem em tudo deve ser substituída por um equilíbrio consensual entre responsabilidades e ganhos nas relações contratantes/fornecedores. De outro lado, seu caráter polêmico, ante as mobilizaçōes sindicais, num ambiente de crise econômica, quando o comportamento das relações capital/trabalho se mostra intransigente e pouco flexível e cujas reivindicações e processos de negociação são resolvidos à sombra da interveniência estatal, vis-à-vis, um regime jurídico-trabalhista conservador e estático, estaria a exigir das empresas uma atividade de maior planejamento na busca de um processo de negociação mais participativo e amortizador dos conflitos entre empresários e representantes sindicais. Neste aspecto, ganha importância a prática dos chamados contratos coletivos de trabalho.

Em suma, o amadurecimento das relações empresas contratantes/fornecedores, no que diz respeito ao estabelecimento de uma postura de parceria e das relações destes para com as representatividades sindicais, em que pesem os interesses dos trabalhadores envolvidos num processo de terceirização, é que iria propiciar num médio ou longo prazo, a formação, o desenvolvimento e a sustentação de novos mercados (criação de micro e pequenas empresas), do padrão de qualidade dos produtos, do nível de empregos e salários, contribuindo, assim, ao abrandamento da crise recessiva por que passa o país.

\section{BIBLIOGRAFIA SUPLEMENTAR}

- BASTOS, Jair Rodriques. Espaço reservado pelo direito positivo brasileito para atıação das empresas locadoras de mão-te-obra. LTR-Revista de Legis lação do Trabaiho e Previdência Social. São Paulo, v. $54, n, 11$, D. $1307-16,1990$.

- CARMO, João do o processo de terceirização e os abusos que estáo sendo cometidos pelas empre sas. LTR-Revista de Legislação do Trabalho e Previdência Social. Suplemento Trabalhista, Săo Paulo, v. 29, , . 07, p. $27-29,1993$.

- COSTA, Thais de Oliveira. Grandes empresas transferem atividades para ex-funcionários. Folha de $S$. Paulo, São Paulo, 19 dez. 1991, Caderno 1, p. 1

- DIEESE, Pesquisa DIEESE, no 7, São Paulo, 1992, $41 \mathrm{p}$

- hOSTALÁCIO, Antônio Maurício et al. A vantagem de ser parceiro. In: Seminário Nacional Terceirizacão \& Parceria - Caminho Inadiável São Paulo, 1992. Co- letânea de textos, publicaçães e artigos sobre.. Săo Paulo: CETTA, 1992, 47 p. p. 1-8

- LEIRIA, Gerōnimo Souto et al. Terceirização passo a passo: o caminho para a administração pública e privada. Porto Alegre: Sagra-DC Luzzatto, 1992 $136 p$.

- _ _ Terceinzação: uma alternativa de flexibilidade empresarial. Porto Alegre: Sagra-DC Luzzato, 1992.

- NETO, Nogueira Domingos de Souza. A contratação por via de empresa interposta e a atividade de telefonia. LTR - Revista de Legislação do Trabalho e Previdência Social. São Paulo, v. 56, n. 10, p. 1223 32 , out. 1992.

- ROMITA, Arion Sayão. A terceirização e o direito do trabalho e Previdência Social. LTR - Revista de Legislação do Trabalho e Previdência Social. São Pau1. v. 53, n. 3, p. $273-79,1992$
- SEIDL, Antônio Carlos, Cresce a opcão por serviço de tezceiros. Folha de S. Paulo, São Paulo, 30 out 1992, Caderno 2, D. 9.

- Seminário Nacional Terceirização \& Parceria Caminho Inadiável 1992, São Paulo, Coletânea de textos, publicações e artigos sobrẹ... São Paulo: CETTA, 1992, $47 \mathrm{p}$.

- Seminário Nacional Terceirização - Parceria para modernidade e competitividade, 1992. São Paulo: IBAP, 1992, 85 p.

- SINDICATO DOS METALÚRGICOS DO ABC PAULISTA. OS trabalhadores e a terceirização. São Bernardo do Campo, 1992, $59 \mathrm{p}$.

- SOUZA, Andréia Alcione de et al. Quando a estratégia empresarial afeta as relaçōes de trabalho: 0 caso do franchising nos Correios. In: ANAIS DO XVII ENANPAD, RH, Salvador, 1993, v. 10. 